\title{
Pappenheimer Body Count
}

National Cancer Institute

\section{Source}

National Cancer Institute. Pappenheimer Body Count. NCI Thesaurus. Code C74616.

The determination of the number of Pappenheimer bodies in a sample. 